\title{
Growth hormone effects on cortical bone dimensions in young adults with childhood-onset growth hormone deficiency
}

\author{
L. Hyldstrup • G. S. Conway • K. Racz • A. Keller • \\ P. Chanson • M. Zacharin • A. L. Lysgaard • \\ A. H. Andreasen • A.-M. Kappelgaard
}

Received: 11 August 2011 / Accepted: 26 October 2011 / Published online: 29 November 2011

(C) The Author(s) 2011. This article is published with open access at Springerlink.com

\begin{abstract}
Summary Growth hormone (GH) treatment in young adults with childhood-onset GH deficiency has beneficial effects on bone mass. The present study shows that cortical bone dimensions also benefit from GH treatment, with endosteal
\end{abstract}

\footnotetext{
L. Hyldstrup $(\bowtie) \cdot$ A. L. Lysgaard

Department of Endocrinology (541),

Hvidovre University Hospital,

DK-2650 Hvidovre, Denmark

e-mail: hyld@dadlnet.dk

\section{G. S. Conway}

Department of Endocrinology and Diabetes,

University College London Hospitals,

London, UK

\section{K. Racz}

2nd Department of Medicine, Semmelweis University,

Budapest, Hungary
}

\section{A. Keller}

Children's Hospital, University of Leipzig,

Leipzig, Germany

\section{P. Chanson}

Service d'Endocrinologie et des Maladies de la Reproduction, and Centre de Référence des Maladies Endocriniennes

Rares de la Croissance, Assistance-Publique Hôpitaux de Paris,

Hôpital de Bicêtre, University Paris-Sud,

Le Kremlin-Bicêtre, France

M. Zacharin

Department of Endocrinology and Diabetes,

Royal Children's Hospital,

Parkville, VIC, Australia

A. H. Andreasen - A.-M. Kappelgaard

GHT Medical Affairs, Global Marketing, Novo Nordisk,

Bagsvaerd, Denmark expansion and increased cortical thickness leading to improved bone strength.

Introduction In young adults with childhood-onset growth hormone deficiency (CO GHD), GH treatment after final height is reached has been shown to have beneficial effects on spine and hip bone mineral density. The objective of the study was to evaluate the influence of $\mathrm{GH}$ on cortical bone dimensions.

Methods Patients ( $n=160$; mean age, 21.2 years; 63\% males) with CO GHD were randomised 2:1 to GH or no treatment for 24 months. Cortical bone dimensions were evaluated by digital x-ray radiogrammetry of the metacarpal bones every 6 months.

Results After 24 months, cortical thickness was increased compared with the controls $(6.43 \%$, CI 3.34 to $9.61 \%$; $p=$ $0.0001)$ and metacarpal index $(\mathrm{MCI})(6.14 \%$, CI 3.95 to $8.38 \% ; p<0.0001)$, while the endosteal diameter decreased $(-4.64 \%$, CI -7.15 to $-2.05 ; p<0.001)$. Total bone width did not change significantly $(0.68 \%$, CI -1.17 to $2.57 \%$; not significant (NS)). A gender effect was seen on bone width $(p<0.0001)$, endosteal diameter $(p<0.01)$ and cortical thickness $(p<0.01)$, but not with MCI (NS).

Conclusions Cortical bone reacts promptly to reinstitution of GH beyond the attainment of final height by increasing the cortical thickness through endosteal bone growth. This leads to a higher peak bone mass and may reduce the risk of cortical bone fragility later in life.

Keywords Bone strength - Cortical bone - Growth hormone deficiency Growth hormone treatment . Metacarpal index

\section{Introduction}

Young adults with childhood-onset growth hormone deficiency (CO GHD) have lower bone mineral density than 
healthy controls $[1,2]$, displaying reduced cortical thickness, cortical cross-sectional area and overall cortical mineral content [3]. Accordingly, an increased susceptibility to fractures compared to population controls has been described in young adults with CO GHD [4-6].

Until recently, patients with CO GHD were only treated with growth hormone $(\mathrm{GH})$ until final adult height was attained, usually up until the age of 15-20 years. The achievement of final adult height, however, occurs much earlier than the acquisition of peak bone mass and muscle strength in both genders, with males achieving these milestones later than females [7]. During the last few years, it has been shown that in addition to stimulating linear growth, GH therapy has important beneficial effects on the accrual of lean body mass and bone mineralisation, past the years of achieving adult height [8]. Indeed, the impact of $\mathrm{GH}$ on bone mass accrual can continue even after discontinuation of therapy for over 1.5 years [9]. These observations suggest that GH treatment should be continued up to the achievement of peak bone mass.

An increase in bone mass in young adults with GHD following GH treatment has been reported in several but not all studies [10, 11]. In adolescents with GHD, Drake et al. reported that continuation of GH therapy after completion of linear growth was associated with a greater accrual of bone mass than no treatment [11]. Most studies have evaluated the effect of GH on trabecular bone compartments (lumbar spine) or regions with mixed bone structure (hip) rather than on cortical bone [12]. In one study, 12 months of GH therapy in adults with CO GHD was associated with increased cortical bone thickness, bone formation and remodelling activity [12], but there are only few data on the effects of GH supplementation on the cortical bone compartment in young adolescents with $\mathrm{CO}$ GHD.

Here we report the findings from a randomised controlled study in which digital x-ray radiogrammetry (DXR) was used to evaluate changes in the cortical bone dimensions of the metacarpals following reintroduction of $\mathrm{GH}$ treatment for 24 months in young adults with confirmed CO GHD after final height was attained.

\section{Methods}

\section{Study design}

This was part of a randomised, controlled, open-label study conducted at 22 sites in 12 countries (Australia, Belgium, France, Germany, Hungary, New Zealand, Norway, Poland, Spain, Sweden, Switzerland, UK) [13]. The primary objective of the study was to evaluate the effect of 24 months of $\mathrm{GH}$ treatment in young adults with $\mathrm{CO}$
GHD on bone mineral density (BMD) in the lumbar spine and hip using dual energy X-ray absorptiometry. In the same study, hand $\mathrm{x}$-rays were obtained to evaluate changes in cortical bone dimensions, as assessed by DXR, during GH treatment. The study was conducted in accordance with Good Clinical Practice guidelines and the Declaration of Helsinki and with approval from appropriate ethical review boards for each study centre.

\section{Patient population}

Young adults (18-25 years; body mass index, BMI, 18$30 \mathrm{~kg} / \mathrm{m}^{2}$ ) diagnosed with CO GHD, on the basis of at least one stimulated test of GH secretion, were included in the trial. All subjects had received $\mathrm{GH}$ treatment during childhood until adult height was attained. Subjects with isolated or only two (including GH) pituitary hormone deficiencies were required to undergo a further provocative GH test after their 16th birthday to confirm the diagnosis. The required replacement therapy apart from GH was performed at the discretion of the single investigator. Subjects with three or more pituitary hormone deficiencies were exempt from further testing. GH testing was carried out according to current consensus guidelines at the time of patient recruitment [14]. Patients were excluded from the study if they had received GH treatment during the month prior to randomisation, but information in the single individual on the time since $\mathrm{GH}$ was discontinued was not available. Other reasons for exclusion were serious cardiac, hepatic or renal disease, uncontrolled hypertension, diabetes, acromegaly, diseases that could affect bone metabolism or any malignant tumour. Female subjects were excluded if pregnant or lactating. For subjects with more than one (other than GH) known deficient hypothalamic-pituitary axis, replacement doses of thyroid, adrenal, gonadal and/or antidiuretic hormone were to have been unchanged for at least 6 months prior to attendance at the screening visit. There were no significant differences between the treatment and control groups regarding use of pituitary substitution therapy [13].

\section{Study protocol}

Patients were randomised (2:1) to either two years' openlabel treatment with GH (Norditropin ${ }^{\circledR}$ SimpleXx ${ }^{\circledR}$, Novo Nordisk, Copenhagen, Denmark) or to an untreated control group. GH was initiated at a starting dose of $0.2 \mathrm{mg}$ /day (males) and $0.4 \mathrm{mg} /$ day (females). The dose was increased to 0.6 and $0.9 \mathrm{mg} /$ day at 1 month and raised again to 1.0 and $1.4 \mathrm{mg} /$ day at 3 months, for males and females, respectively, for the remainder of the study. The higher GH dose was given to females since they require higher doses than males to achieve normal insulin-like growth factor-1 
levels [15]. Dose reduction due to GH-related side effects was allowed at the discretion of the investigator. A single daily subcutaneous injection of $\mathrm{GH}$ was administered at bedtime using a cartridge pen (NordiPen ${ }^{\circledR}$, Novo Nordisk, Copenhagen, Denmark). Patients in the control group received no treatment during the study. The trial was conducted as an open-label study and not placebo controlled, since it was deemed unethical to subject young adults to daily placebo injections for 24 months. Each patient attended the clinic at the screening visit (1-5 weeks before randomisation), the randomisation visit, and at 1,3 , 6, 12, 18 and 24 months. The study did not include any information on dietary intake prior to treatment, and there were no specific dietary requirements for the duration of the study.

\section{Measurements}

Radiographs were obtained at months $0,6,12,18$ and 24 . DXR analysis (Sectra Imtec AB, Linkoping, Sweden) requires a plain or digital radiograph of the non-dominant hand [16]. In this study, plain radiographs were used and sent to a central, blinded reading facility (The Osteoporosis Unit, Hvidovre University Hospital, Copenhagen, Denmark). In order to secure standardised x-rays, a radiographic manual was delivered to all centres, describing positioning of the hand and forearm, film type, a film/ focus distance of $100 \mathrm{~cm}$, and the use of $50 \mathrm{kV}$ and 4 $8 \mathrm{mAs}$ as exposure parameters. The radiographs were captured as digital images using a flat-bed scanner $(600 \times 600 \mathrm{dpi}, 12$-bit greyscale $)$ and three regions of interest (metacarpals 2, 3 and 4) were automatically identified. In each of the three regions, the bone width and inner diameter were measured symmetrically around the centre of the metacarpals at a resolution of 117 lines $/ \mathrm{cm}$; the length ' $\mathrm{L}$ ' is $1.5 \mathrm{~cm}$ for metacarpal 4 $1.8 \mathrm{~cm}$ for metacarpal 2 (Fig. 1). Bone width, endosteal diameter, cortical thickness, metacarpal index (MCI) and the areal cross-sectional moment of inertia (CSMI) $\left(\mathrm{CSMI}=\pi \times\left[\left(\right.\right.\right.$ bone width $\left.\left.^{4}-(\text { inner diameter })^{4}\right] / 64\right)$ were then calculated. The latter was included as a geometric indicator of bone strength. The short-term precision of DXR has previously been determined in 40 pre- and postmenopausal women, demonstrating a coefficient of variance $(\mathrm{CV})$ value of $0.65 \%$ [17].

\section{Statistical methods}

Primary analysis of the treatment effect was performed with an ANCOVA model including correction for baseline level and the treatment effect on the logarithmic transformed changes from baseline.

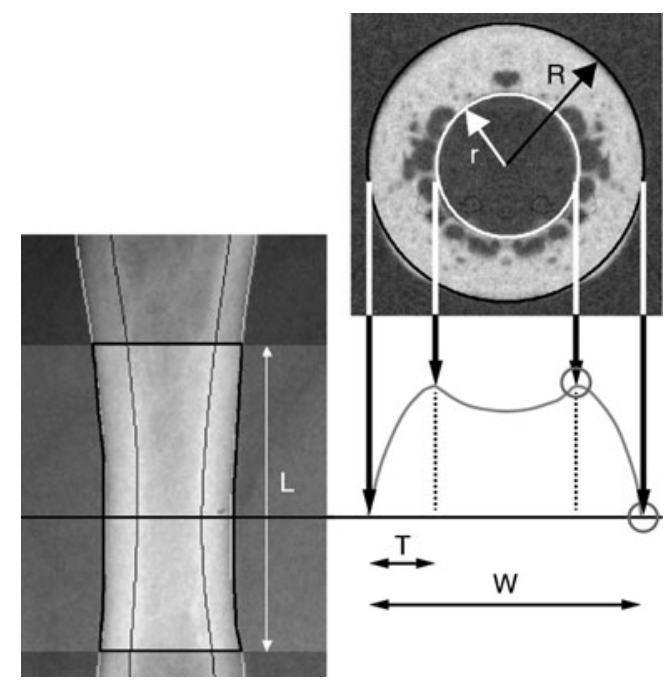

Fig. 1 Principles of digital x-ray radiogrammetry. Using a standard $\mathrm{x}$ ray, the region of interest is automatically detected. From the density curve (right), the external and internal diameters are detected (117 lines $/ \mathrm{cm})$. The reported bone width $(W)$, cortical thickness $(T)$ and endosteal diameter are the averages of these measurements. Coefficient of variation (CV) $0.65 \%$

Analyses of the influence of gender, height, weight and BMI were made by including them one by one in a repeated measurement ANCOVA model with treatment, visit, interaction between treatment and visit and baseline level as fixed effects and subject as a random effect. The correlations between radiogrammetric and densitometric measurements were estimated in simple linear regression models.

\section{Results}

\section{Baseline demographics}

Patients $(n=160)$ were randomised to receive GH $(n=109)$ or no treatment $(n=51)$. Baseline patient demographics as well as baseline values for bone parameters by sex and treatment group were not different between groups (Table 1). There were 19 (17.4\%) withdrawals in GH-treated patients and $11(21.6 \%)$ withdrawals in the control group. The most common reason for withdrawal from the study was patient decision. Only five patients withdrew due to adverse events, details of which can be found in the previous publication [13]. Mean GH dose (standard deviation, SD) at study end was $17.9 \mu \mathrm{g} / \mathrm{kg} /$ day (6.3).

\section{Efficacy}

In young adults with $\mathrm{CO}$ GHD previously treated with GH until final height, reinstitution of GH for 24 months was associated with a marked increase in cortical 
Table 1 Baseline characteristics of randomised patients by treatment group, mean (SD)

\begin{tabular}{|c|c|c|c|c|c|c|}
\hline & \multicolumn{3}{|c|}{ Growth hormone group $(n=109)$} & \multicolumn{3}{|c|}{ Control group $(n=51)$} \\
\hline & Male & Female & Total & Male & Female & Total \\
\hline$n(\%)$ & $65(60)$ & $44(40)$ & $109(100)$ & $34(67)$ & $17(33)$ & $51(100)$ \\
\hline Age (years) & $21.0(2.4)$ & $21.2(2.2)$ & $21.1(2.3)$ & $21.4(2.2)$ & $21.4(2.1)$ & $21.4(2.1)$ \\
\hline Height (cm) & $172.4(7.4)$ & $155.8(7.2)$ & $165.7(11.0)$ & $170.3(7.6)$ & $162.1(8.7)$ & $167.5(8.8)$ \\
\hline Weight (kg) & $69.6(13.6)$ & $54.6(11.1)$ & $63.5(14.6)$ & $68.5(13.0)$ & $59.6(10.7)$ & $65.5(12.9)$ \\
\hline BMI $\left(\mathrm{kg} / \mathrm{cm}^{2}\right)$ & $23.3(3.5)$ & $22.4(3.4)$ & $22.9(3.5)$ & $23.5(3.6)$ & $22.6(3.3)$ & $23.2(3.5)$ \\
\hline Bone width (cm) & $0.820(0.076)$ & $0.727(0.049)$ & $0.783(0.080)$ & $0.813(0.073)$ & $0.726(0.076)$ & $0.784(0.084)$ \\
\hline Endosteal diameter (cm) & $0.459(0.71)$ & $0.416(0.65)$ & $0.442(0.72)$ & $0.427(0.088)$ & $0.409(0.074)$ & $0.421(0.083)$ \\
\hline Cortical thickness $(\mathrm{cm})$ & $0.186(0.027)$ & $0.161(0.024)$ & $0.176(0.029)$ & $0.200(0.028)$ & $0.163(0.027)$ & $0.188(0.032)$ \\
\hline Metacarpal index $(\mathrm{mm} / \mathrm{mm})$ & $0.44(0.06)$ & $0.43(0.07)$ & $0.44(0.06)$ & $0.48(0.08)$ & $0.44(0.07)$ & $0.47(0.08)$ \\
\hline $\begin{array}{l}\text { Areal cross-sectional moment of inertia } \\
\left(\mathrm{mm}^{4} \times 1,000\right)\end{array}$ & $21(8)$ & $12(3)$ & $17(7)$ & $20(7)$ & $13(5)$ & $18(7)$ \\
\hline
\end{tabular}

No significant difference between groups was found in demographic data or radiographic measurements

thickness compared to a matched control group (treatment difference [GH-control] [95\% CI]) $(6.43 \%$ [95\% CI, 3.34, 9.61], $p<0.0001)$. This increase was the result of both cortical expansion and endosteal bone growth. However, while the external diameter increased equally in GH-treated and control groups (estimated treatment difference $0.68 \%$ [ $95 \%$ CI $-1.17,2.57]$, NS) a significant treatment difference in favour of $\mathrm{GH}$ was found in the endosteal diameter, with a greater reduction in $\mathrm{GH}$-treated as compared to untreated patients $(-4.64 \mathrm{~mm}$ [95\% CI $7.15,2.05], p=0.0006$ ) (Fig. 2). A gender effect, which was not correlated to any treatment effect $(p=0.057)$ with cortical thickness being greater in males than in females (0.19 vs. 0.18), was also demonstrated. Finally, a significant influence of height was found $(p=0.0002)$; the taller a subject, the greater the cortical thickness.

As an index of bone biomechanical competence, the CSMI was calculated showing a significant increase over time in both GH-treated patient and controls $(p<0.0001)$ (Fig. 2). The difference between the two groups did not reach statistical significance, although there was a trend towards a greater increase in GH-treated patients (treatment difference, $4.53[-2.96,12.59], p=0.2404)$. A significant effect of baseline BMD was found $(-0.23[-0.31$ to -0.14$)]$, $p<0.0001$ ).

GH treatment was associated with greater increase in MCI compared to the control group where this value remained more or less constant during the 24-month study period (estimated treatment difference, $6.14 \%$ $[3.95,8.38], p<0.0001$ ) (Fig. 3). In order to evaluate to what extent the radiogrammetry measurements reflected skeletal changes in general, the correlations between radiogrammetric and densitometric measurements are shown in Table 2.

\section{Discussion}

The main finding of the present study was that GH substitution, after achievement of final height in young adults with $\mathrm{CO}$ GHD, is associated with a significant increase in cortical bone thickness. The observed reduction in endosteal diameter in GH-treated patients in this study suggests that the increase results from endosteal bone growth rather from periosteal apposition. While there is no one single cause of bone fragility, fewer or thinner trabeculae and thin cortices, all play their part in low peak bone density [18]. In early adulthood, material and structural strength is maintained by remodelling, the focal replacement of old with new bone. During ageing, concurrent bone formation on the outer (periosteal) cortical bone surface partly compensates for bone loss. Although the structural basis of bone fragility is determined partly by genetic and environmental factors, growth during the pubertal and early adult years has a significant influence on bone strength in later years. Hence, a GH-induced reduction in endosteal diameter may, potentially, have beneficial effects on cortical bone strength $[19,20]$, thereby reducing the risk of bone fragility later in life [21]. Limited data are currently available on the growth patterns of cortical bone during normal adolescence and in patients with CO GHD, and our findings therefore also contribute to the understanding of cortical bone development during growth.

There are few data on changes in cortical bone density with GH therapy in patients with CO GHD. Using peripheral quantitative computed tomography, Schweizer et al. [22] reported that 12 months of GH therapy was associated with an increase in both outer and inner diameters of the radius, as well as decreased cortical 
a

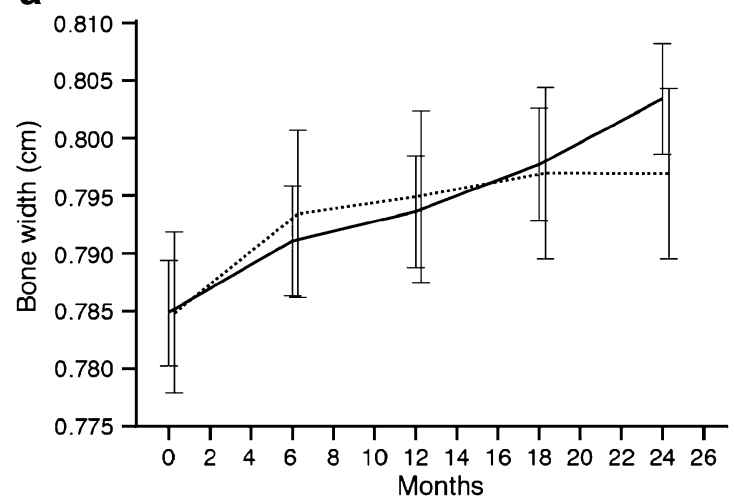

C

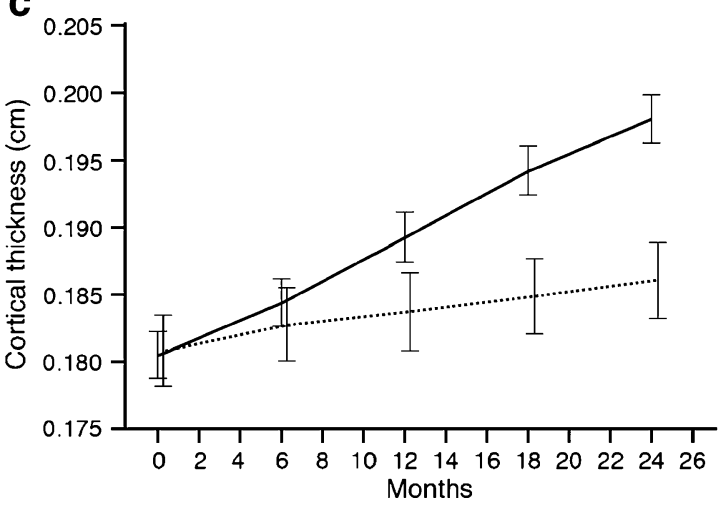

Fig. 2 Changes in metacarpal bone dimensions over 24 months (estimated mean $\pm 95 \%$ confidence interval). Solid line growth hormone treatment group, dashed line untreated group. a Bone width

thickness. The impact of GH on cortical bone might be different after epiphyseal closure and cessation of longitudinal bone growth.

The findings of this study are in agreement with the earlier reported densitometry findings of the same population [13], showing an increase in lumbar spine BMD of $3.5 \%$ and total hip BMD of $2.4 \%$ during GH therapy. Interestingly, some studies report a reduction in bone

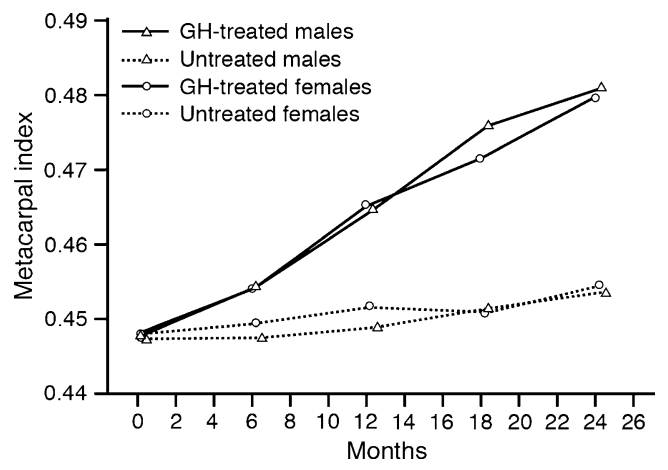

Fig. 3 Change in metacarpal index $(2 \mathrm{CT} / W$ [millimetres per millimetre]) by treatment group and by gender


(centimetres), b endosteal diameter (centimetres), $\mathbf{c}$ cortical thickness (centimetres), d CSMI $(\times 1,000)$. $p$ values indicate treatment difference from baseline to end of trial. $p<0.0001$

density during the first year of GH therapy, which is likely caused by an increase in remodelling space and a temporary reduction in bone mass and size [3, 23, 24]. Longer treatment periods show increased bone formation as the areal bone density tends to fall during the first 6 months of treatment and reaches baseline levels again between 6 and 12 months [13]. In the present study, in which only cortical bone is encountered, a linear increase in cortical area was observed from the very start of treatment. Despite only a marginal increase in bone width being observed in our study, there was a pronounced reduction in the inner bone diameter. This reduction leads to an increase in cortical thickness and a tendency towards an increase in strength, as calculated by the CSMI. Furthermore, our data support that the initial loss of areal bone density due to increased remodelling was only marginal in cortical bone compared with BMD of the spine and total hip, where a trabecular component was part of the region of interest. Histological evaluation after $\mathrm{GH}$ treatment for 1 year in $\mathrm{CO}$ GHD patients has shown increased trabecular bone turnover, but not a positive bone balance [25]. However, a different pattern is likely to be seen in cortical bone and after a longer duration of treatment [13]. 
Table 2 Correlations between cortical thickness measured by radiogrammetry at the metacarpal bones and densitometry measurements at the spine and hip [13]

\begin{tabular}{lllr}
\hline & & $R^{\wedge} 2$ & $p$ value \\
\hline Cortical thickness at baseline vs. BMD spine at baseline & Entire group & 0.25 & $<0.0001$ \\
Cortical thickness at baseline vs. BMD total hip at baseline & Entire group & 0.18 & $<0.0001$ \\
Change in cortical thickness vs. change in BMD spine & GH-treated & 0.07 & 0.0103 \\
Change in cortical thickness vs. change in BMD spine & Untreated & 0.09 & 0.0806 \\
Change in cortical thickness vs. change in BMD total hip & GH-treated & 0.13 & 0.0005 \\
Change in cortical thickness vs. change in BMD total hip & Untreated & 0.02 & 0.3824 \\
\hline
\end{tabular}

To obtain normal bone growth and optimal peak bone mass, the interplay of $\mathrm{GH}$ and gonadal hormones through late childhood and puberty is essential. Consequently, GHD as well as hypopituitarism in adults is associated with low bone mass and an increased risk of fractures [26-29]. While the impact of gonadal hormones on bone growth is diminished after epiphyseal closure, GH continues to play an important role in reaching peak bone mass several years later. Consequently, patients with CO GHD are lacking an important factor if $\mathrm{GH}$ treatment is stopped when final height is reached. Until now this has been the normal procedure for most CO GHD patients. Discontinuation of GH treatment after attainment of adult height may compromise further bone growth [11,30]. Indeed, changes in cortical bone when GH treatment is reinstituted, as found in the present study, are the reverse of the age-related changes in bone seen in later adult life [31] and may therefore leave the CO GHD patients better protected against cortical bone fragility as they age. The changes in cortical bone growth may also have been influenced by dietary factors. No data on diet are available, but the randomisation process is likely to have minimised such bias.

Studies evaluating changes in lumbar spine BMD indicate that despite a lower areal density in CO GHD patients, the volumetric density is not lower [3]. Consequently, CO GHD leads to insufficient growth of bone size, but not low bone mineral content [32]. The increased fracture risk described in $\mathrm{CO}$ GHD [5] is consequently related to small bones rather than to low BMD.

Using radiogrammetry, comparison with normative data from other studies should be interpreted with caution due to the potential influence of differences in exposure settings, but the settings used in the present study do not differ substantially from those used by Toledo and Jergas [33]. A comparison of cortical dimensions in the GHD patients with the female normative data from the study reported by Toledo and Jergas [33] showed smaller bones with a thinner cortical shell in the female CO GHD patients. After 2 years of GH therapy, bone dimensions of treated females approached those of healthy women, but no gender difference following treatment was found in the ratio of cortical thickness to bone width, as measured by MCI.
Furthermore, while there was a similar increase in bone width in GH-treated subjects and controls, changes in the endosteal diameter were significantly greater in the GHtreated subjects. This might indicate that the main effect of $\mathrm{GH}$ on cortical bone growth is mainly on the inner surfaces.

DXR allows detailed non-invasive evaluation of cortical bone dimensions and can therefore be used as a supplement to bone densitometry. It measures the metacarpal dimensions with high precision, and therefore, also smaller changes can be detected. The present data clearly show that this technique provides meaningful information on cortical bone dimensions using simple radiographs of the hand. Also, the effect of GH can be detected after 12 months of treatment compared with conventional densitometry, where the effects are only detectable much later due to an initial decline in areal bone density. A potential weakness of the method is that only metacarpal bone is measured and may therefore not be representative of cortical bone changes in general. However, it has previously been shown that the same measurements at the metacarpals predict fracture risk at both hip and spine [34]. It is therefore likely that the measured changes reflect a generalised effect on bone, at least in patients with osteoporosis. In the present study, significant correlations between baseline cortical thickness and baseline BMD of the hip and spine, as well as changes in cortical thickness and changes in spine and hip BMD, were found, indicating that this is probably also the case for CO GHD patients. Further studies are needed to evaluate this finding in more depth.

In conclusion, these data showed that in patients with CO GHD, 2 years' treatment with GH after attainment of final height was associated with beneficial changes in cortical bone dimensions which are the reverse of those seen with age-related bone loss. Provided that the improvements in cortical thickness are maintained over longer time periods, GH treatment of CO GHD patients might reduce the risk of cortical bone fragility later in life.

Acknowledgements The authors would like to thank Watermeadow Medical (Witney, UK) for their editorial assistance, which was supported by Novo Nordisk. 
Conflicts of interest This study was supported by Novo Nordisk A/S, Denmark. L. Hyldstrup received research grants from Novo Nordisk to conduct the DXR analyses.

M. Zacharin has from time to time received educational grants from Novo Nordisk but has received no funding support in relation to this work.

A.-M. Kappelgaard is an employee of Novo Nordisk. A. Andreasen works as a statistical consultant for Novo Nordisk. The Service d'Endocrinologie et des Maladies de la Reproduction of Hôpital Bicêtre has received educational and research grants from Novo Nordisk, Merck-Serono, Pfizer and Ipsen.

P. Chanson is a member of the HypoCSS (Hypopituitary Control and Complication Study) International Advisory Board, sponsored by Eli Lilly.

G. Conway is a member of an advisory board for, and receives speaker fees from, Novo Nordisk.

K. Racz, A. Keller and A. Lysgaard have no conflicts of interest to declare.

Open Access This article is distributed under the terms of the Creative Commons Attribution Noncommercial License which permits any noncommercial use, distribution, and reproduction in any medium, provided the original author(s) and source are credited.

\section{References}

1. Kaufman JM, Taelman P, Vermeulen A, Vandeweghe M (1992) Bone mineral status in growth hormone-deficient males with isolated and multiple pituitary deficiencies of childhood onset. J Clin Endocrinol Metab 74:118-123

2. Boot AM, van der Sluis IM, Krenning EP, de Muinck KeizerSchrama SM (2009) Bone mineral density and body composition in adolescents with childhood-onset growth hormone deficiency. Horm Res 71:364-371

3. de Boer H, Blok GJ, van Lingen A, Teule GJ, Lips P, van der Veen EA (1994) Consequences of childhood-onset growth hormone deficiency for adult bone mass. J Bone Miner Res 9:1319-1326

4. Holmer H, Svensson J, Rylander L, Johannsson G, Rosen T, Bengtsson BA, Thoren M, Hoybye C, Degerblad M, Bramnert M, Hagg E, Engstrom BE, Ekman B, Thorngren KG, Hagmar L, Erfurth EM (2007) Fracture incidence in GH-deficient patients on complete hormone replacement including GH. J Bone Miner Res 22:1842-1850

5. Bouillon R, Koledova E, Bezlepkina O, Nijs J, Shavrikhova E, Nagaeva E, Chikulaeva O, Peterkova V, Dedov I, Bakulin A, Oganov V, Attanasio AF (2004) Bone status and fracture prevalence in Russian adults with childhood-onset growth hormone deficiency. J Clin Endocrinol Metab 89:4993-4998

6. Baroncelli GI, Bertelloni S, Sodini F, Saggese G (2002) Lumbar bone mineral density at final height and prevalence of fractures in treated children with GH deficiency. J Clin Endocrinol Metab $87: 3624-3631$

7. Bonjour JP, Theintz G, Buchs B, Slosman D, Rizzoli R (1991) Critical years and stages of puberty for spinal and femoral bone mass accumulation during adolescence. J Clin Endocrinol Metab 73:555-563

8. Mauras N (2010) GH use in the transition of adolescence to adulthood. Endocr Dev 18:109-125

9. Biller BM, Sesmilo G, Baum HB, Hayden D, Schoenfeld D, Klibanski A (2000) Withdrawal of long-term physiological growth hormone $(\mathrm{GH})$ administration: differential effects on bone density and body composition in men with adult-onset GH deficiency. J Clin Endocrinol Metab 85:970-976
10. Underwood LE, Attie KM, Baptista J (2003) Growth hormone (GH) dose-response in young adults with childhood-onset GH deficiency: a two-year, multicenter, multiple-dose, placebocontrolled study. J Clin Endocrinol Metab 88:5273-5280

11. Drake WM, Carroll PV, Maher KT, Metcalfe KA, CamachoHubner C, Shaw NJ, Dunger DB, Cheetham TD, Savage MO, Monson JP (2003) The effect of cessation of growth hormone $(\mathrm{GH})$ therapy on bone mineral accretion in GH-deficient adolescents at the completion of linear growth. J Clin Endocrinol Metab $88: 1658-1663$

12. Bravenboer N, Holzmann P, de Boer H, Roos JC, van der Veen EA, Lips P (1997) The effect of growth hormone (GH) on histomorphometric indices of bone structure and bone turnover in GH-deficient men. J Clin Endocrinol Metab 82:1818-1822, Erratum in: J Clin Endocrinol Metab 1997;82:2238

13. Conway GS, Szarras-Czapnik M, Racz K, Keller A, Chanson P, Tauber M, Zacharin M (2009) Treatment for 24 months with recombinant human $\mathrm{GH}$ has a beneficial effect on bone mineral density in young adults with childhood-onset GH deficiency. Eur J Endocrinol 160:899-907

14. Growth Hormone Research Society (1998) Consensus guidelines for the diagnosis and treatment of adults with growth hormone deficiency: summary statement of the growth hormone research society workshop on adult growth hormone deficiency. J Clin Endocrinol Metab 83:379-381

15. Bengtsson BA, Abs R, Bennmarker H, Monson JP, Feldt-Rasmussen U, Hernberg-Stahl E, Westberg B, Wilton P, Wüster C (1999) The effects of treatment and the individual responsiveness to growth hormone $(\mathrm{GH})$ replacement therapy in $665 \mathrm{GH}$-deficient adults. KIMS Study Group and the KIMS International Board. J Clin Endocrinol Metab 84:3929-3935

16. Jørgensen JT, Andersen PB, Rosholm A, Bjarnason NH (2000) Digital X-ray radiogrammetry: a new appendicular bone densitometric method with high precision. Clin Physiol 20:330 335

17. Black DM, Palermo L, Sorensen T, Jørgensen JT, Lewis C, Tylavsky F, Wallace R, Harris E, Cummings SR (2001) A normative reference database study for Pronosco X-posure System. J Clin Densitom 4:5-12

18. Seeman E (2002) Pathogenesis of bone fragility in women and men. Lancet 359:1841-1850

19. Ammann P, Rizzoli R (2008) Bone strength and its determinants. Osteoporos Int 14(suppl 3):13-18

20. Wang Q, Seeman E (2008) Skeletal growth and peak bone strength. Best Pract Res Clin Endocrinol Metab 22:687-700

21. Wang Q, Ghasem-Zadeh A, Wang XF, Iuliano-Burns S, Seeman E (2011) Trabecular bone of growth plate origin influences both trabecular and cortical morphology in adulthood. J Bone Miner Res 26:1577-1583

22. Schweizer R, Martin DD, Schwarze CP, Binder G, Georgiadou A, Ihle J, Ranke MB (2003) Cortical bone density is normal in prepubertal children with growth hormone $(\mathrm{GH})$ deficiency, but initially decreases during $\mathrm{GH}$ replacement due to early bone remodeling. J Clin Endocrinol Metab 88:5266-5272

23. Bex M, Bouillon R (2003) Growth hormone and bone health. Horm Res 60(suppl 3):80-86

24. Högler W, Briody J, Moore B, Lu PW, Cowell CT (2005) Effect of growth hormone therapy and puberty on bone and body composition in children with idiopathic short stature and growth hormone deficiency. Bone 37:642-650

25. Brixen K, Hansen TB, Hauge E, Vahl N, Jørgensen JO, Christiansen JS, Mosekilde L, Hagen C, Melsen F (2000) Growth hormone treatment in adults with adult-onset growth hormone deficiency increases iliac crest trabecular bone turnover: a 1-year, double-blind, randomized, placebo-controlled study. J Bone Miner Res 15:293-300 
26. Giustina A, Mazziotti G, Canalis E (2008) Growth hormone, insulinlike growth factors, and the skeleton. Endocr Rev 29:535-559

27. Canalis E (1997) Insulin-like growth factors and osteoporosis. Bone 21:215-216

28. Vestergaard P, Jørgensen JO, Hagen C, Hoeck HC, Laurberg P, Rejnmark L, Brixen K, Weeke J, Andersen M, Conceicao FL, Nielsen TL, Mosekilde L (2002) Fracture risk is increased in patients with GH deficiency or untreated prolactinomas - a casecontrol study. Clin Endocrinol (Oxf) 56:159-167

29. Holmer H, Svensson J, Rylander L, Johannsson G, Rosén T, Bengtsson BA, Thorén M, Höybye C, Degerblad M, Bramnert M, Hägg E, Engström BE, Ekman B, Thorngren KG, Hagmar L, Erfurth EM (2007) Fracture incidence in GH-deficient patients on complete hormone replacement including GH. J Bone Miner Res 22:1842-1850

30. Baroncelli GI, Bertelloni S, Sodini F, Saggese G (2004) Longitudinal changes of lumbar bone mineral density (BMD) in patients with GH deficiency after discontinuation of treatment at final height; timing and peak values for lumbar BMD. Clin Endocrinol (Oxf) 60:175-184

31. Chen H, Zhou X, Shoumura S, Emura S, Bunai Y (2010) Ageand gender-dependent changes in three-dimensional microstructure of cortical and trabecular bone at the human femoral neck. Osteoporos Int 21:627-636

32. Högler W, Shaw N (2010) Childhood growth hormone deficiency, bone density, structures and fractures: scrutinizing the evidence. Clin Endocrinol (Oxf) 72:281-289

33. Toledo VA, Jergas M (2006) Age-related changes in cortical bone mass: data from a German female cohort. Eur Radiol 16:811-817

34. Bouxsein ML, Palermo L, Yeung C, Black DM (2002) Digital X-ray radiogrammetry predicts hip, wrist and vertebral fracture risk in elderly women: a prospective analysis from the study of osteoporotic fractures. Osteoporos Int 13:358-365 